\title{
Reconnection electric field estimates and dynamics of high-latitude boundaries during a substorm
}

\author{
T. Pitkänen ${ }^{1}$, A. T. Aikio ${ }^{1}$, A. Kozlovsky ${ }^{2}$, and O. Amm ${ }^{3}$ \\ ${ }^{1}$ Department of Physical Sciences, University of Oulu, P.O. Box 3000, 90014, Finland \\ ${ }^{2}$ Sodankylä Geophysical Observatory, Sodankylä, Finland \\ ${ }^{3}$ Finnish Meteorological Institute, Helsinki, Finland
}

Received: 7 November 2008 - Revised: 3 April 2009 - Accepted: 4 May 2009 - Published: 12 May 2009

\begin{abstract}
The dynamics of the polar cap and the auroral oval are examined in the evening sector during a substorm period on 25 November 2000 by using measurements of the EISCAT incoherent scatter radars, the north-south chain of the MIRACLE magnetometer network, and the Polar UV Imager.

The location of the polar cap boundary (PCB) is estimated from electron temperature measurements by the mainland low-elevation EISCAT VHF radar and the $42 \mathrm{~m}$ antenna of the EISCAT Svalbard radar. A comparison to the poleward auroral emission (PAE) boundary by the Polar UV Imager shows that in this event the PAE boundary is typically located $0.7^{\circ}$ of magnetic latitude poleward of the PCB by EISCAT. The convection reversal boundary (CRB) is determined from the 2-D plasma drift velocity extracted from the dual-beam VHF data. The CRB is located $0.5-1^{\circ}$ equatorward of the PCB indicating the existence of viscous-driven antisunward convection on closed field lines.

East-west equivalent electrojets are calculated from the MIRACLE magnetometer data by the 1-D upward continuation method. In the substorm growth phase, electrojets together with the polar cap boundary move gradually equatorwards. During the substorm expansion phase, the Harang discontinuity (HD) region expands to the MLT sector of EISCAT. In the recovery phase the PCB follows the poleward edge of the westward electrojet.

The local ionospheric reconnection electric field is calculated by using the measured plasma velocities in the vicinity of the polar cap boundary. During the substorm growth phase, values between 0 and $10 \mathrm{mV} / \mathrm{m}$ are found. During the late expansion and recovery phase, the reconnection electric
\end{abstract}

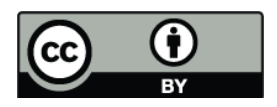

Correspondence to: T. Pitkänen (timo.pitkanen@oulu.fi) field has temporal variations with periods of 7-27 min and values from 0 to $40 \mathrm{mV} / \mathrm{m}$. It is shown quantitatively, for the first time to our knowledge, that intensifications in the local reconnection electric field correlate with appearance of auroral poleward boundary intensifications (PBIs) in the same MLT sector. The results suggest that PBIs (typically $1.5 \mathrm{~h}$ MLT wide) are a consequence of temporarily enhanced longitudinally localized magnetic flux closure in the magnetotail.

Keywords. Ionosphere (Polar ionosphere) - Magnetospheric physics (Auroral phenomena; Magnetosphereionosphere interactions)

\section{Introduction}

Magnetic reconnection on the dayside magnetopause and in the nightside magnetotail are the main factors controlling the solar wind energy transfer into the magnetosphere and ionosphere. As first suggested by Dungey (1961), during southward interplanetary magnetic field (IMF) conditions, the low latitude reconnection on the dayside magnetopause creates open field lines that are transported to the magnetotail by the solar wind flow. Subsequent closing of the field lines in the magnetotail reconnection, which can occur either at the distant neutral line (DNL) or during substorm conditions at the near-Earth neutral line (NENL), and the following sunward motion of these closed field lines complete the magnetospheric convection cycle.

The magnetospheric convection maps into the ionosphere where plasma flows antisunward across the polar cap and returns to dayside at lower latitudes roughly within the dawn and dusk auroral oval. Depending on the balance between the dayside and nightside reconnection rates, the amount of open

Published by Copernicus Publications on behalf of the European Geosciences Union. 
magnetic flux changes affecting the polar cap size. When the dayside reconnection rate exceeds the nightside rate, the polar cap expands as the open flux increases. In the opposite situation the polar cap contracts as the open flux decreases (Siscoe and Huang, 1985; Cowley and Lockwood, 1992).

During southward IMF conditions, the two-cell convection pattern is established, and a non-zero $B_{y}$ component leads to an asymmetry in the convection cells (e.g. Cowley and Lockwood, 1992). For pure northward IMF, the dayside magnetic reconnection occurs poleward of the cusp, creating reverse convection cells as the pre-existing open flux is circulating from one side to the other in the tail lobe. However, with non-zero $B_{y}$ also closed field lines on the equatorward side of the cusps may reconnect (Tanaka, 1999, and references therein).

According to Faraday's law, changes in the amount of open magnetic flux $\Phi_{B}$ threading the polar cap are related to the electromotive force, which can be separated into the dayside and nightside reconnection voltages (e.g. Siscoe and Huang, 1985; Milan et al., 2003; Milan, 2004)

$$
\frac{d \Phi_{B}}{d t}=V_{\text {day }}+V_{\text {night }}
$$

The reconnection voltages are the integrals of the day- and nightside reconnection electric fields along those portions of the polar cap, which map to the reconnection sites. In a stationary situation, where magnetic flux is opened the same amount in the dayside as it is closed in the nightside, the sum of these voltages is zero. In this paper, we study only the nightside reconnection electric field $E_{r}$, which if known, can be integrated along the nightside polar cap boundary (PCB) to get the corresponding reconnection voltage

$$
V_{\text {night }}=\int_{\text {night }} \boldsymbol{E}_{r} \cdot d \boldsymbol{l}
$$

Theoretical work by Vasyliunas (1984) showed that plasma flow across the polar cap boundary can be utilized to determine the reconnection electric field in the ionosphere and further in the magnetotail. The reconnection electric field along the polar cap boundary can be written as

$$
\boldsymbol{E}_{r}=\left(\boldsymbol{v}_{b}-\boldsymbol{v}_{p}\right) \times \boldsymbol{B},
$$

where $\boldsymbol{v}_{b}$ is the polar cap boundary velocity (normal to the boundary), $\boldsymbol{v}_{p}$ is the plasma flow velocity normal to the PCB and $\boldsymbol{B}$ is the magnetic field. Hence a duskward electric field in the magnetotail corresponds to magnetic flux closure (see e.g. Østgaard et al., 2005; Hubert et al., 2006). In the following, we use a sign convention where positive reconnection electric field means flux closure and velocities in the equatorward direction are positive.

The first attempt to estimate the ionospheric reconnection electric field by using Eq. (3), was made by de la Beaujardiere et al. (1991). Sondrestrom incoherent scatter radar
(ISR) in the midnight sector was used in a meridional scanning mode and the PCB was identified by using electron density contour levels caused by auroral precipitation. The orientation of the PCB was inferred from all-sky images. Blanchard et al. $(1996,1997)$ utilized the same method, but additionally Blanchard et al. (1996) used a technique based on $630.0 \mathrm{~nm}$ auroral emissions.

Global optical imaging and ground-based radar measurements were combined to calculate the reconnection electric field in the nightside by Østgaard et al. (2005). They used the poleward edge of the auroral oval extracted from the IMAGE FUV wide band imaging (WIC) camera images together with the EISCAT ISR electron temperature measurements to identify the PCB and its orientation and velocity. Plasma velocity was obtained from EISCAT measurements.

The ISR-based methods described above are restricted in local time (MLT) coverage. However, their spatial and temporal resolution in locating the PCB is typically better than in other methods. Another approach to estimate the reconnection rate is to apply Eq. (1) to get the reconnection voltages. Milan et al. (2003) inferred the polar cap boundary at all local times from global optical images by the Polar UV Imager and by the spectral widths of the SuperDARN HF radars, by using low-altitude orbiting satellite particle data as guidance. The reconnection voltages were then calculated by using the change in the amount of open flux. Milan et al. checked the validity of the method by comparing the dayside reconnection voltage values to the estimates calculated by using Eqs. (2) and (3), and found a good agreement between the results of the two methods. Recently, Hubert et al. (2006) used global optical images by the IMAGE FUV SI12 instrument and plasma convection measurements of SuperDARN radars to get the reconnection voltages by using Eqs. (2) and (3).

When the two-cell convection pattern prevails, the antisunward flow in the polar cap and the sunward return flow are separated by a velocity shear called the convection reversal boundary (CRB). Intuitively, the CRB represents the polar cap boundary, since the open polar cap field lines are convecting with the plasma across the polar cap from the dayside to the nightside and the flow with the reconnected closed field lines returns back to the dayside. However, there are evidence of small amount of antisunward convection on closed field lines, indicating the PCB location poleward of the CRB (Senior et al., 1994; Sotirelis et al., 2005, and references therein).

As a consequence of magnetosphere-ionosphere coupling, the current systems which are embedded in the convection pattern and auroral zone involve both horizontal and fieldaligned currents (FACs). At the Harang discontinuity (HD) in the premidnight sector, the dominating eastward electrojet changes to the westward electrojet (e.g. Koskinen and Pulkkinen, 1995). The electrojets (and associated FACs) produce the magnetic convection reversal boundary (MCRB).

In this paper, we study some specific aspects of the reconnection process that can be related to high-latitude 
boundaries, by using EISCAT incoherent scatter radar measurements. We estimate the ionospheric reconnection electric field in the evening sector during a substorm on 25 November 2000, by applying the method introduced by Vasyliunas (1984). Plasma velocity, and location, orientation, and velocity of the polar cap boundary are determined from EISCAT measurements. The EISCAT PCB is compared with Polar UVI images. In addition, the convection reversal boundary is extracted from the EISCAT data and these boundaries are then studied in the framework of the electrojets, including the Harang discontinuity region. Finally, the reconnection electric field estimates are calculated.

\section{Methods and data analysis}

\subsection{Ground-based measurements}

Throughout this study, we use the aacgm (altitude adjusted corrected geomagnetic) coordinate system, in which any two points connected by a magnetic field line have the same coordinates (Baker and Wing, 1989).

The mainland EISCAT VHF radar located near Troms $\varnothing$ (aacgm: $66.58^{\circ}$ lat, $102.9^{\circ}$ lon) measured in a low-elevation $\left(30^{\circ}\right)$ dual beam mode with the west beam (VHFa) pointing nearly towards geomagnetic north and the east beam (VHFb) pointing towards geographic north (azimuth $17.5^{\circ}$ and $0.5^{\circ}$ to the west from ggnorth, respectively, see Fig. 1). In addition, the $42 \mathrm{~m}$ antenna of the EISCAT Svalbard radar (ESR), (aacgm: $75.22^{\circ}$ lat, $111.9^{\circ}$ lon) was measuring field-aligned.

The VHF data were obtained with a latitudinal coverage of $70.3-78.2^{\circ}$ for the VHFa in 15 range gates, and 70.1-78.5 for the $\mathrm{VHFb}$ in 16 range gates. The latitudinal resolution decreased polewards from 0.4 to $0.8^{\circ}$ and from 0.3 to $0.6^{\circ}$ for the $\mathrm{VHFa}$ and $\mathrm{VHFb}$, respectively. Both radar beams covered the altitude range of $233-1032 \mathrm{~km}$ with gate height separation increasing from 23 to $83 \mathrm{~km}$ in the poleward direction. The ESR $42 \mathrm{~m}$ field-aligned data were measured from the altitude range of about $90-880 \mathrm{~km}$ with the height resolution decreasing from the lowest E-region values of $3 \mathrm{~km}$ up to $37 \mathrm{~km}$ high in the F-region.

The EISCAT measurements covered the time interval 17:00-22:00 UT on 25 November 2000, and yield the four basic ionospheric parameters: electron density $N_{e}$, electron and ion temperature $T_{e}$ and $T_{i}$, and the line-of-sight (1-o-s) ion velocity $V_{i}$. The magnetic midnight at Troms $\emptyset$ is at about 21:30 UT.

The north-south chain of the MIRACLE magnetometer network (Fig. 1) was used to estimate the ionospheric currents. East-west equivalent electrojets were calculated from magnetic $\mathrm{X}$ component data by using the 1-D upward continuation method by Vanhamäki et al. (2003).

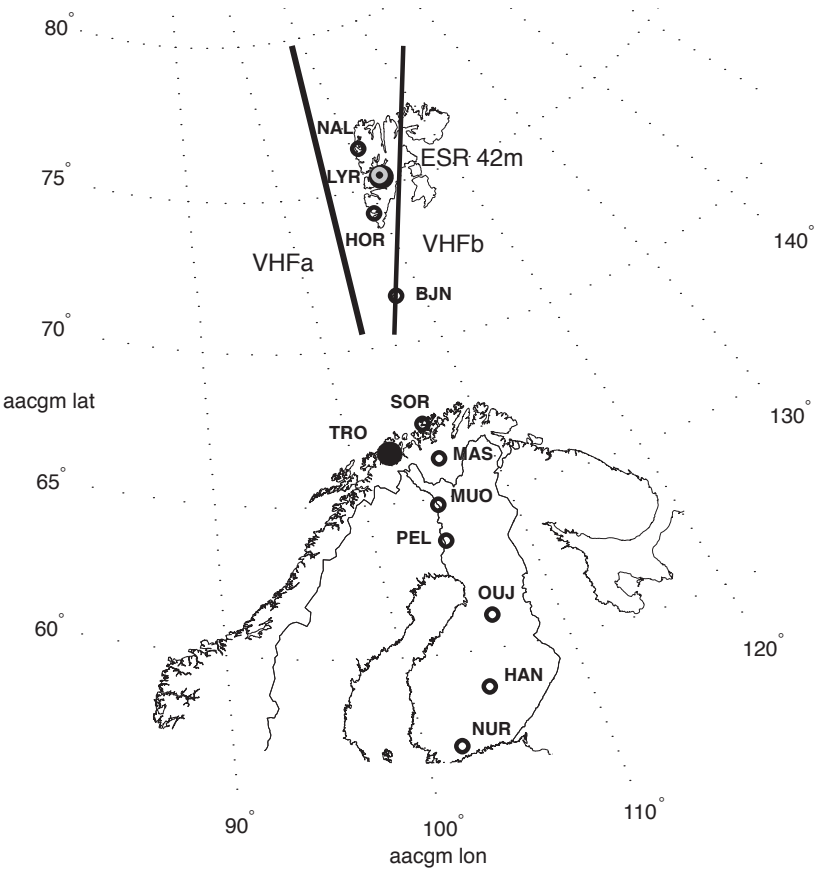

Fig. 1. Black: EISCAT radar locations and radar beam geometry used on 25 November 2000. The VHF radar is located near Troms $\varnothing$ (TRO) and the field-aligned ESR $42 \mathrm{~m}$ antenna of the ESR system close to Longyearbyen (LYR) on Svalbard. Black lines are the ground level projections of the two VHF radar beams. Open circles: Stations of the MIRACLE north-south magnetometer chain.

\subsection{Polar cap boundary, plasma velocity and reconnec- tion electric field}

The polar cap boundary location was estimated by using the method introduced by Aikio et al. (2006) and used also in Aikio et al. (2008). The method uses electron temperature $T_{e}$ measurements from a low-elevation EISCAT VHF radar and the field-aligned ESR $42 \mathrm{~m}$ antenna. The $T_{e}$ in the nightside F-region can be enhanced within the auroral oval due to collisional heating of particle precipitation. When the PCB is situated between the mainland and Svalbard, the field-aligned ESR $42 \mathrm{~m}$ provides a $T_{e}$ height profile in the polar cap. The low-elevation radar, in this case the dual beam VHF, measures a $T_{e}$ profile which is affected by both latitudinal and altitude variations in the temperature. By subtracting the polar cap $T_{e}$ height profile from the low-elevation $T_{e}$ profile, a $\Delta T_{e}$ latitude profile is obtained, in which the polewardmost latitude where $\Delta T_{e}$ is positive is taken as the PCB (see Aikio et al., 2006, for details).

The VHF data were first integrated to $60 \mathrm{~s}$ and the ESR $42 \mathrm{~m}$ measurements to $128 \mathrm{~s}$. During the studied time interval, the electron temperature at Svalbard did not show any significant variations, which made a longer integration period possible. Consequently, to reduce variance in the 


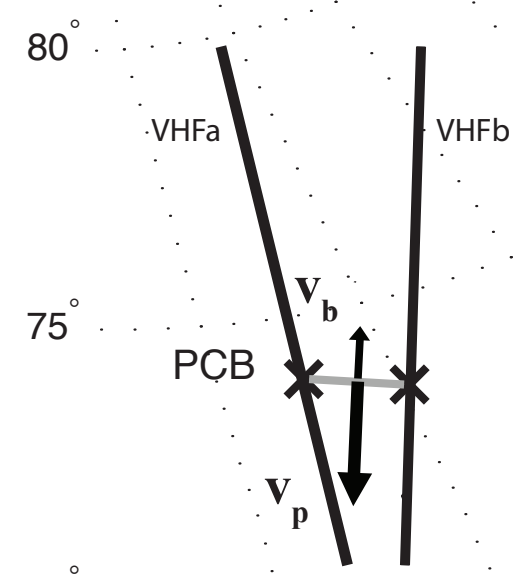
$70^{\circ}$

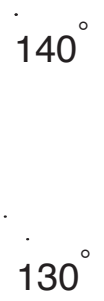

$120^{\circ}$

Fig. 2. Schematic presentation of the measurement. The black crosses show the PCB for the two VHF beams and the solid grey line the orientation of the PCB. Vectors $\boldsymbol{v}_{b}$ and $\boldsymbol{v}_{p}$ are the velocities of the polar cap boundary and plasma along the PCB normal, respectively.

reference polar cap height profile, the ESR $42 \mathrm{~m}$ data were averaged to $1 \mathrm{~h}$ time resolution. The PCB was determined for the two beams of the VHF separately, which allowed estimation of the PCB orientation.

The 2-dimensional $\boldsymbol{E} \times \boldsymbol{B}$ plasma drift velocity was calculated from the 1-o-s ion velocities of the two VHF radar beams. When doing this, it must be assumed that there are no longitudinal variations in velocity between the beams and that the field-aligned ion velocity is zero. The longitudinal separation of the two radar beams increased from 97 to $195 \mathrm{~km}$ with latitude. The 2-D velocity vectors were placed in the middle of the gate pairs. For calculating the magnetic field at different latitudes, the IGRF/DGRF-model was used (http://modelweb.gsfc.nasa.gov/models/cgm/cgm.html).

The reconnection electric field was calculated by Eq. (3). A schematic presentation of the situation is shown in Fig. 2. The 2-D plasma velocity as interpolated at the PCB latitude and the components of the plasma velocity $\left(\boldsymbol{v}_{p}\right)$ and the PCB velocity $\left(\boldsymbol{v}_{b}\right)$ along the PCB normal were calculated. For the estimate of the polar cap boundary velocity, 5-min running means at the 1-min resolution of the PCB location were first calculated. These data were further interpolated to $30-\mathrm{s}$ resolution to obtain the PCB velocity estimates at the same time instants as the plasma velocity measurements. It was assumed that the PCB maintains its orientation as it moves in latitude along the magnetic meridian during the one-minute interval, though this condition may not always be true as pointed out by Østgaard et al. (2005).

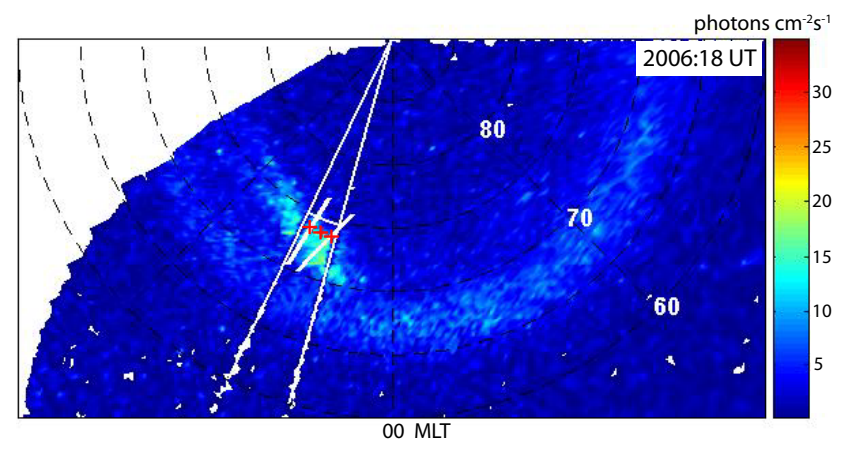

Fig. 3. UV image taken at 20:06:18 UT on 25 November 2000. The PAE boundary is marked by a white longitudinal arc connecting the white 40-min MLT sector boundaries. The EISCAT PCBs are marked by red crosses (both beams and their average).

\subsection{Comparison of EISCAT and Polar UVI data}

For the studied interval 17:00-22:00 UT, on 25 November global images of the northern auroral oval were provided by the UV Imager of the Polar satellite (Torr et al., 1995). The UV Imager was taking images with an integration time of $37 \mathrm{~s}$ using the LBHl filter (Lyman-Birge-Hopfield long, $160-180 \mathrm{~nm}$ ). The emission luminosity in the LBHl wavelength band is practically directly proportional to the energy flux of the precipitating electrons. An emission altitude of $120 \mathrm{~km}$ is assumed for the LBHl emissions. For the images, only the line of sight correction has been done which takes into account the increased emission when looking through a longer path length of the atmosphere at large angles away from nadir. The dayglow has not been removed since it is northern winter.

The images were collected continuously, excluding short periods at 18:18-18:22 UT, 19:04-19:09 UT and 20:2120:25 UT, when the instrument was taking background images. Since the data had a time resolution of $37 \mathrm{~s}$, one complete minute time interval could include two or three successive images. Therefore, to compare the UVI data with the EISCAT data, an image sequence of one frame per minute was generated by selecting the image overlapping most with the corresponding one-minute period to represent the time interval.

To estimate the poleward emission boundary PAE, a 40min wide MLT sector containing both of the VHF radar beams was selected from each image. Then for each sector, a latitude profile of longitudinally averaged emission intensities were calculated with a resolution of half a degree in latitude. The latitude profile was interpolated further to a resolution of $0.1^{\circ}$ and the location of the PAE was determined by using a ratio value of $0.3 \mathrm{UV}_{\max }$, where $\mathrm{UV}_{\text {max }}$ is the intensity maximum in the corresponding latitude profile. Sometimes the emissions remained weak and formed a flat latitude profile, resulting in unreasonable values of the PAE. 


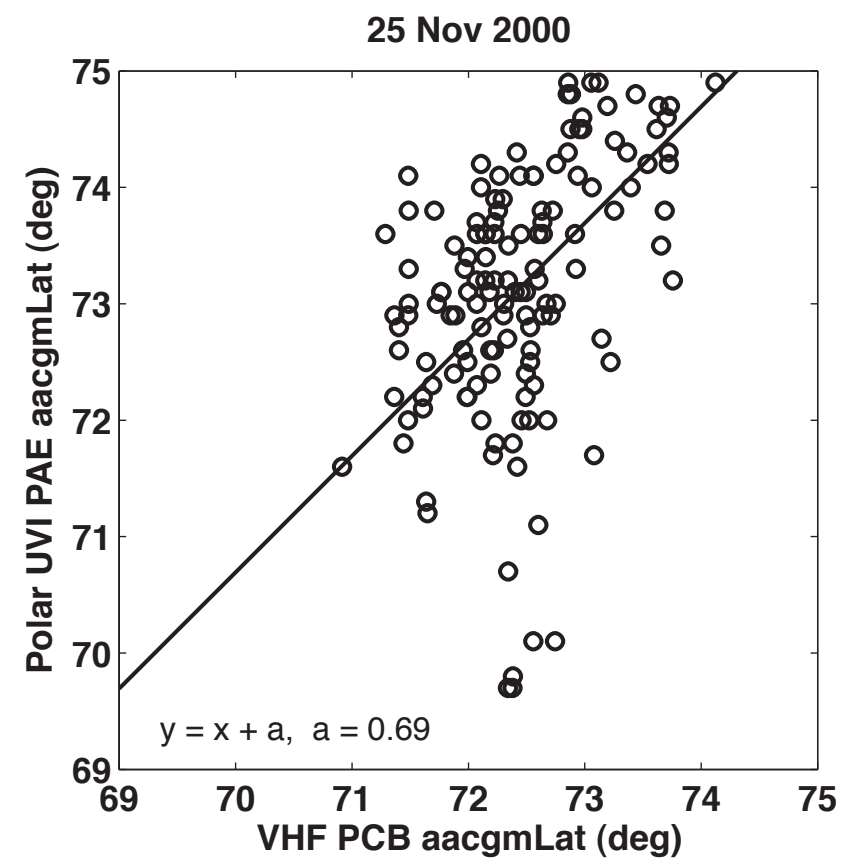

Fig. 4. Comparison of the polar cap boundary estimates by EISCAT VHF and Polar UVI. Linear fit of the form $y=x+a$ has been applied giving for the constant a-value $a=0.69$. The Pearson correlation coefficient $r=0.42$.

In those cases, a threshold value of 4.3 photons $\mathrm{cm}^{-2} \mathrm{~s}^{-1}$ was used.

Both methods for locating the PAE boundary have been used earlier, in Baker et al. (2000) and Aikio et al. (2006). Baker et al. (2000) found for the Polar UVI images that the optimal ratio and threshold values were $0.3 \mathrm{UV}_{\max }$ and $4.3 \mathrm{~cm}^{-2} \mathrm{~s}^{-1}$, respectively, when comparing the PAE and the DMSP b5e boundaries. In addition, when comparing Viking UV with DMSP data, Kauristie et al. (1999) used the ratio value of $0.5 \mathrm{UV}_{\max }$ (full-width half maximum). However, they stated that the value 1/e 0.37 could be even better in cases not hampered by background scatter, which is close to the value 0.3 obtained by Baker et al. (2000).

An example of an UVI image taken at 20:06:18 UT is presented in Fig. 3. The calculated PAE latitude $\left(74.7^{\circ}\right)$ is marked by a white arc connecting the MLT sector boundaries. The PCBs from the VHFa $\left(73.7^{\circ}\right), \mathrm{VHFb}\left(73.6^{\circ}\right)$ and their average $\left(73.65^{\circ}\right)$ are marked by red crosses. In this case the latitudinal difference between the average VHF PCB and PAE was $1.1^{\circ}$.

In total 138 VHF PCB and UVI PAE pairs could be extracted from the studied substorm time interval 17:0022:00 UT. Only those point pairs were included for which both estimates were below $75^{\circ}$ cgmlat, which is the upper limit for the EISCAT $\Delta T_{e}$-method. In addition, the amount of point pairs available was reduced by about an hour data gap in the VHF PCB data between 17:52-18:57 UT (5-min

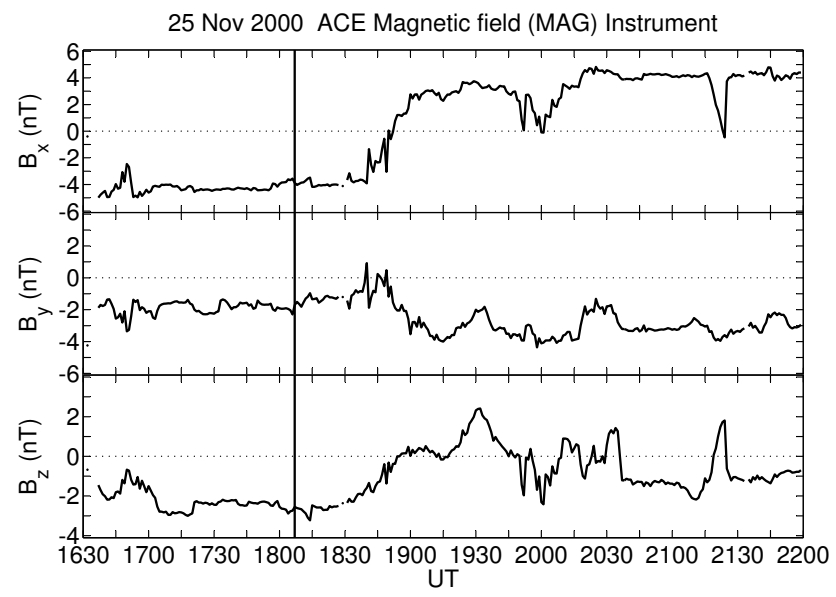

Fig. 5. IMF components measured in GSM by the ACE satellite $\left(X_{\mathrm{GSM}} \sim 224 R_{E}\right.$ ) delayed to the bow shock nose. Vertical line at 18:07 UT indicates the substorm onset time. See details in the text.

running means of the two data sets are visible in Fig. 8). The result is shown as a scatter plot in Fig. 4. Ideally, the points would lie in the $y=x$ curve, but in this event, after making a fit of the form $y=x+a$, where $a$ is a constant, the UVI PAE appeared to be located typically $0.69^{\circ}$ cgmlat poleward of the VHF PCB. The Pearson correlation coefficient $r$ calculated for the scatter data set is $r=0.42$.

We can account a few tenths of a degree of this discrepancy to originate from the method used in VHF PCB determination. By default, the PCB is determined as the polewardmost latitude where the $\Delta T_{e}$-curve with errorbars stays above zero, giving somewhat lower latitude values than the curve without errorbars would give (see Aikio et al., 2006). The original latitudinal resolution of the VHF measurements causes at maximum $0.6-0.7^{\circ}$ uncertainty in the PCB location.

Nominally, the field-of-view (f-o-v) resolution of the Polar UV Imager is approximately $0.04^{\circ} \times 0.04^{\circ}$ (Torr et al., 1995) corresponding typically an ionospheric resolution to $0.3^{\circ}$ lat. However, the despun platform has wobble in one direction, which decreases the UVI resolution in that direction by a factor of 10, in the worst case (Parks et al., 1997). This is probably the most important factor contributing to the scatter, since the wobble was along the 10:00-22:00 MLT line, which is approximately perpendicular to the PAE boundary. In addition, a some contribution may arise from the spatial averaging of the UVI PAE intensities. In the case that the UVI PAE boundary is tilted away from the latitudinal direction in the selected MLT sector, the calculated latitude profile of longitudinally averaged emission intensities is broadened polewards. As a result the calculated UVI PAE boundary would be located somewhat poleward of the true PAE boundary at the EISCAT longitude. 
(a)

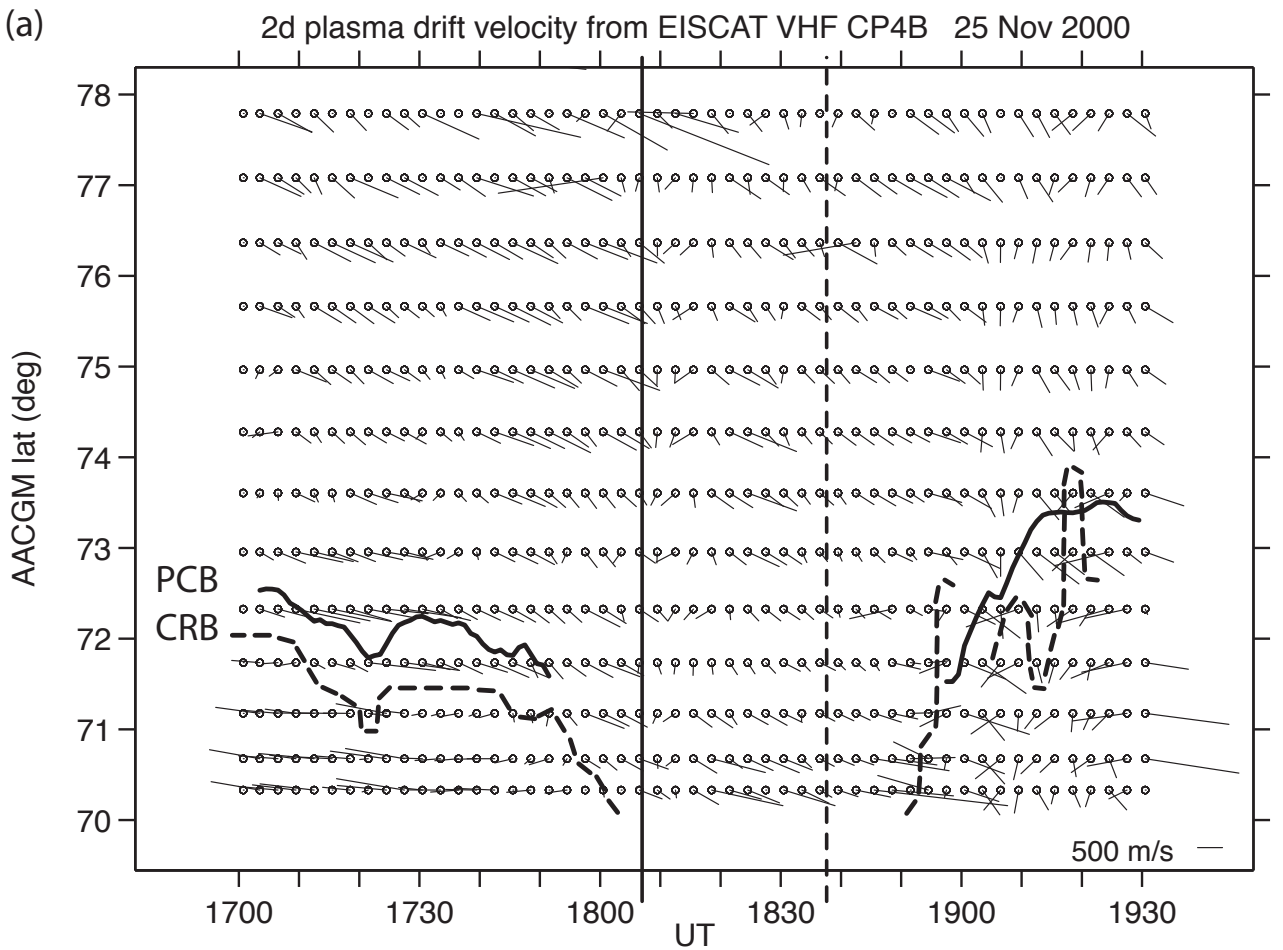

(b) 2d plasma drift velocity from EISCAT VHF CP4B 25 Nov 2000

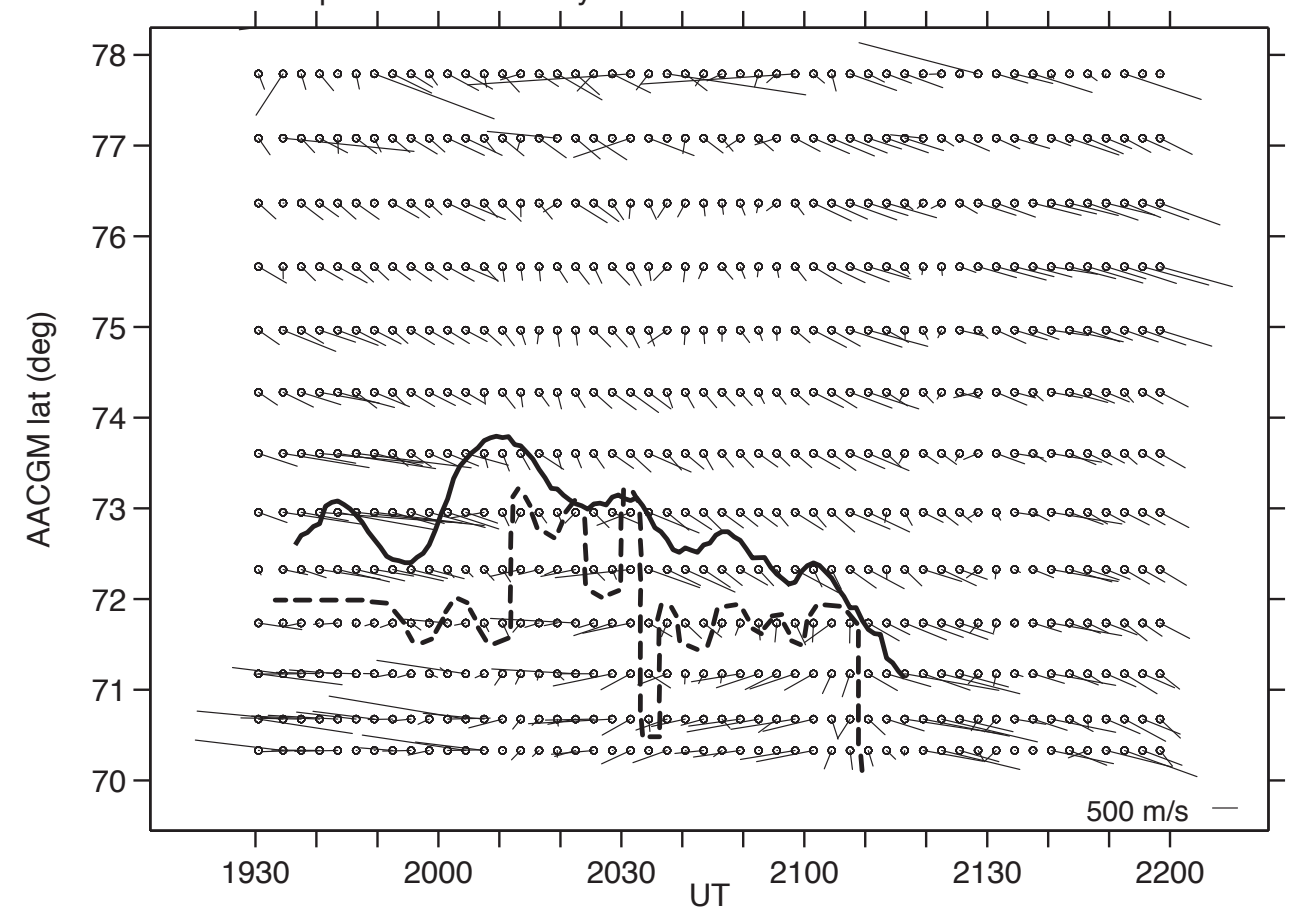

Fig. 6. Plasma drift velocity derived from the dual beam EISCAT VHF data. Only every third 1-min velocity measurement is plotted. The black solid curve indicates the 5-min running mean of the VHF polar cap boundary. The dashed curve is the plasma convection reversal boundary determined from the plasma velocity vectors. The vertical solid line at 18:07 UT indicates the substorm onset occuring at about $2 \mathrm{~h}$ MLT east of EISCAT ( 22:40 MLT) and the dashed line 31 min later the substorm expansion in association with the Harang discontinuity region to the EISCAT MLT. 


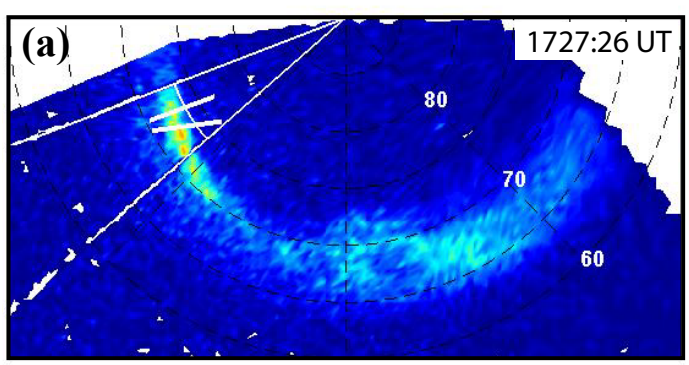

00 MLT

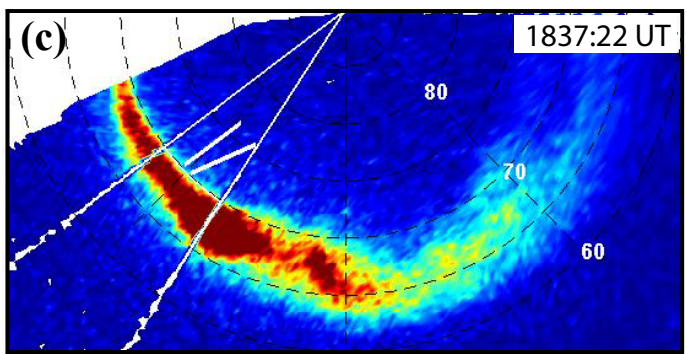

$00 \mathrm{MLT}$

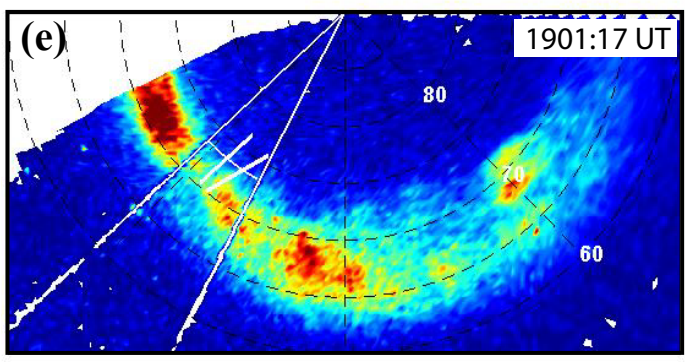

00 MLT

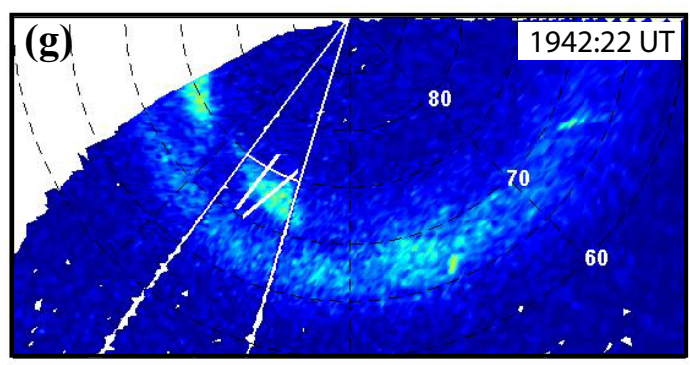

00 MLT

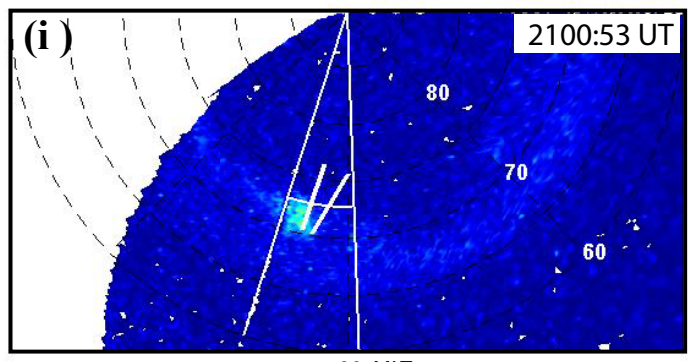

00 MLT

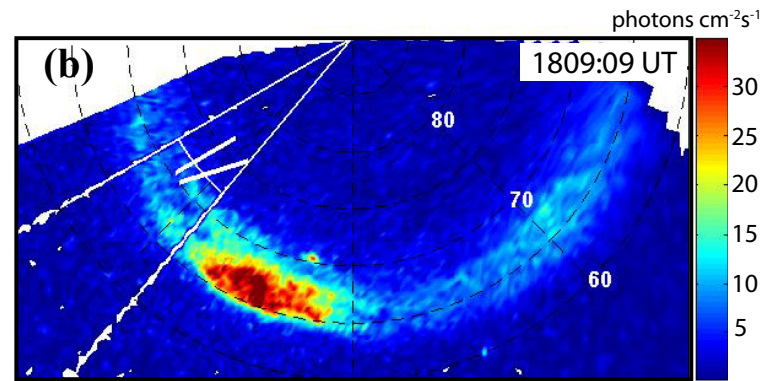

00 MLT

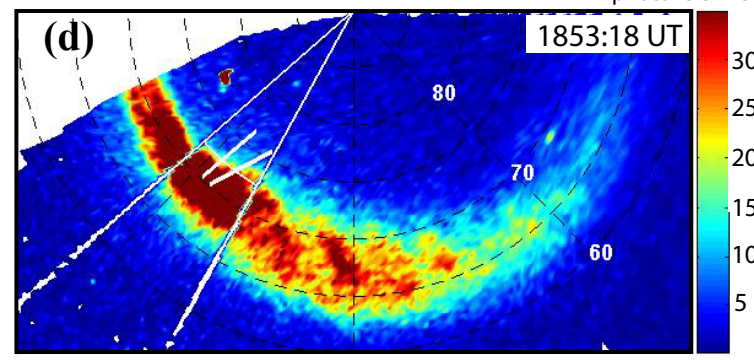

photons $\mathrm{cm}^{-2} \mathrm{~s}^{-1}$

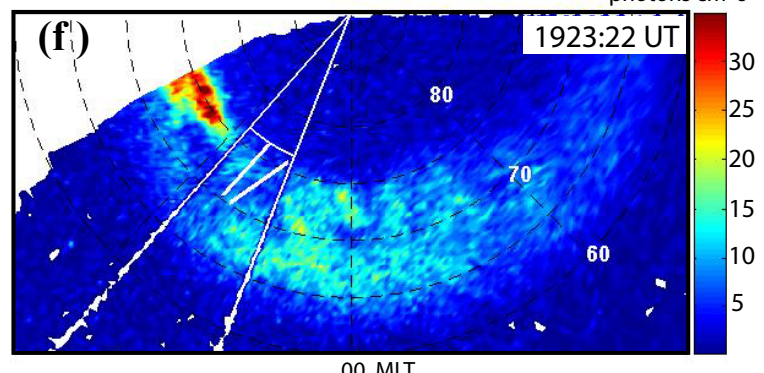

photons $\mathrm{cm}^{-2} \mathrm{~s}^{-1}$

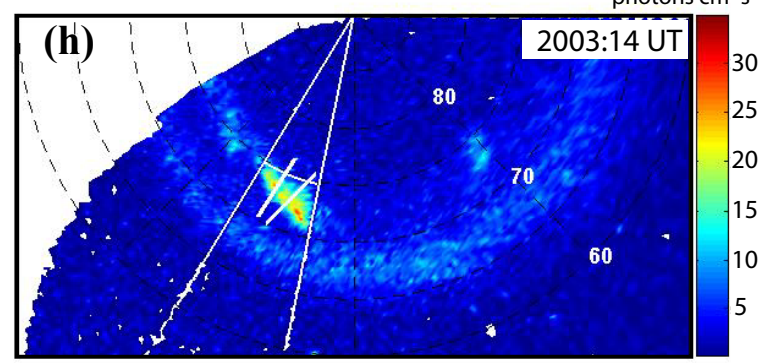

00 MLT

photons $\mathrm{cm}^{-2} \mathrm{~s}^{-1}$

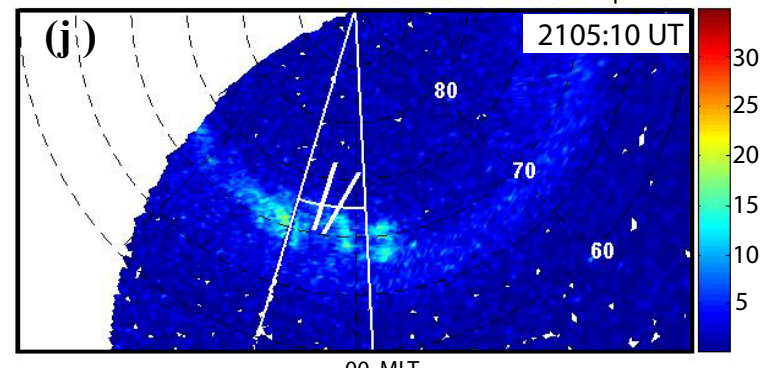

$00 \mathrm{MLT}$

Fig. 7. Selected set of Polar UVI frames showing the general substorm evolution on 25 November 2000. The PAE boundary is marked by a white arc connecting the EISCAT MLT sector boundaries. Two straight white lines in the sector indicate the EISCAT VHF radar beams. See details in the text. 


\section{Substorm on 25 November 2000}

\subsection{Plasma convection}

Figure 5 shows the solar wind IMF measured by the ACE satellite. A dynamic time delay based on a combination of minimum variance and cross product phase front normal determination techniques (Weimer et al., 2008a,b, and references therein), has been calculated to take into account the solar wind propagation from the ACE location $\left(X_{\mathrm{GSM}} \sim 224 R_{E}\right)$ to the Earth's bow shock nose $\left(X_{\mathrm{GSM}} \sim 14 R_{E}\right)$ (http://omniweb.gsfc.nasa.gov/form/ sc_merge_min1.html). The prevailing average solar wind velocity was $400 \mathrm{~km} / \mathrm{s}$.

During 14:00-18:54 UT the IMF $B_{z}$ component remained mainly weakly southwards, creating favourable conditions for magnetospheric substorms. A northward turning of $B_{z}$ started at about 18:45 UT and $B_{z}$ remained weakly positive until 20:36 UT except during 19:48-20:29 UT. The $B_{y}$ component remained negative practically during the whole period.

The plasma velocity vectors calculated from the EISCAT VHF data are presented in Fig. 6. The solid black curve is the 5-min running mean of the VHF polar cap boundary at 1-min resolution, and the dashed curve is the plasma convection reversal boundary (CRB) determined from the plasma velocity vectors. Note that only every third velocity measurement is plotted for the sake of clarity.

The EISCAT measurements started at 17:00 UT and showed a typical evening cell convection pattern with the convection reversal boundary at $72^{\circ}$ cgmlat. The polar cap boundary was located about $0.5^{\circ}$ cgmlat poleward of the CRB. The polar cap boundary moved equatorwards, which is a signature of a substorm growth phase. The CRB followed closely the motion of the PCB. At 17:52 UT the PCB was abruptly displaced to the south and our method could not see it anymore, and a little bit later also the CRB disappeared from the field of view of the VHF radar.

In Fig. 7 a selected set of UVI frames are presented to show the general evolution of the substorm. Most of the frames were selected for reasons that become clear in Sect. 3.5 and may not coincide with the time instants discussed here. Figure 7a was taken during the growth phase of the substorm. The time and location of the substorm onset was determined from the Polar UVI images. At about 18:07 UT the substorm expansion started around 22:40 MLT by a sudden brightening of aurora on a 40-min wide MLT sector in the equatorward oval (not shown). This was followed by a magnetic Pi2 pulsation burst at 18:08 UT, detected by the SAMNET Borok (Russia) mid-latitude magnetometer station $\left(54.1^{\circ}\right.$ cgmlat, $113.3^{\circ}$ cgmlon, data not shown). The of the order of 1-min delay between the auroral signature and the Pi2 burst is consistent with earlier observations of propagation-related delays (Liou et al., 2000).
Here the Borok station was located about $1 \mathrm{~h}$ MLT west of the substorm onset region.

Figure $7 \mathrm{~b}$ shows the situation two minutes after the onset, when the substorm had expanded poleward and toward west and east. In about $30 \mathrm{~min}$ the substorm expansion had progressed so that intense auroral precipitation had intruded into the EISCAT local time from the east (Fig. 7c). At about 18:53 UT the convection reversal boundary reappeared from the south to the EISCAT f-o-v together with the PCB and they both moved polewards (Fig. 6a). During 18:57-19:06 and 19:22-19:31 UT the convection pattern was very dynamic probably violating the assumption of a uniform ion flow between the VHF radar beams. These periods are visible as gaps in the CRB.

The beginning of the recovery phase at about 19:08 UT was determined from the start of the decrease in total integrated westward equivalent current of MIRACLE stations (data not shown). The PCB continued proceeding polewards until 19:23 UT (Fig. 6a and 7f). This is consistent with the observations by Milan et al. (2003), who found that the polar cap area was decreasing due to the poleward contracting PCB in the recovery phase, even after the substorm associated auroral activity had faded away. During the slightly overlapping gaps in the CRB between 19:22-19:34 UT and in the PCB data between 19:31-19:35 UT, the boundaries had moved equatorwards about half a degree and 0.7 degree, respectively. The equatorward motion of the polar cap boundary turned poleward at 19:54 UT and lasted until 20:10 UT before turning equatorward again (Fig. 6b). During the studied time interval, the CRB followed the motion of the PCB and was located $0.5-1^{\circ}$ equatorward of the PCB.

\subsection{Boundaries and equivalent currents}

The equivalent currents with the boundaries are shown in Fig. 8. The red curve indicates the 5-min running average of the UVI PAE boundary. The solid and dashed black curves are the VHF PCB and the CRB, respectively. For the sake of clarity, the convection reversal boundary after the onset of the substorm expansion has been left out (see Fig. 6). The white line marks the magnetic convection reversal boundary (MCRB) determined from the equivalent currents. In the premidnight sector until 20:25 UT ( 23:00 MLT), a value of $0 \mathrm{~mA} / \mathrm{m}$ was used for MCRB. After 20:25 UT, when the westward electrojet was dominating, the $-50 \mathrm{~mA} / \mathrm{m}$ value (corresponding to about $-30 \mathrm{nT}$ in the $\mathrm{X}$ component) followed the poleward boundary better.

During the substorm growth phase before 18:07 UT, the VHF PCB, the CRB, and the UVI PAE boundary were clearly located poleward of the eastward electrojet region and the magnetic convection reversal boundary. The boundaries showed roughly similar equatorward motion in association with the gradually equatorward expanding evening sector eastward electrojet (EEJ) pattern. The PAE boundary showed greater variations including a sudden leap by two 


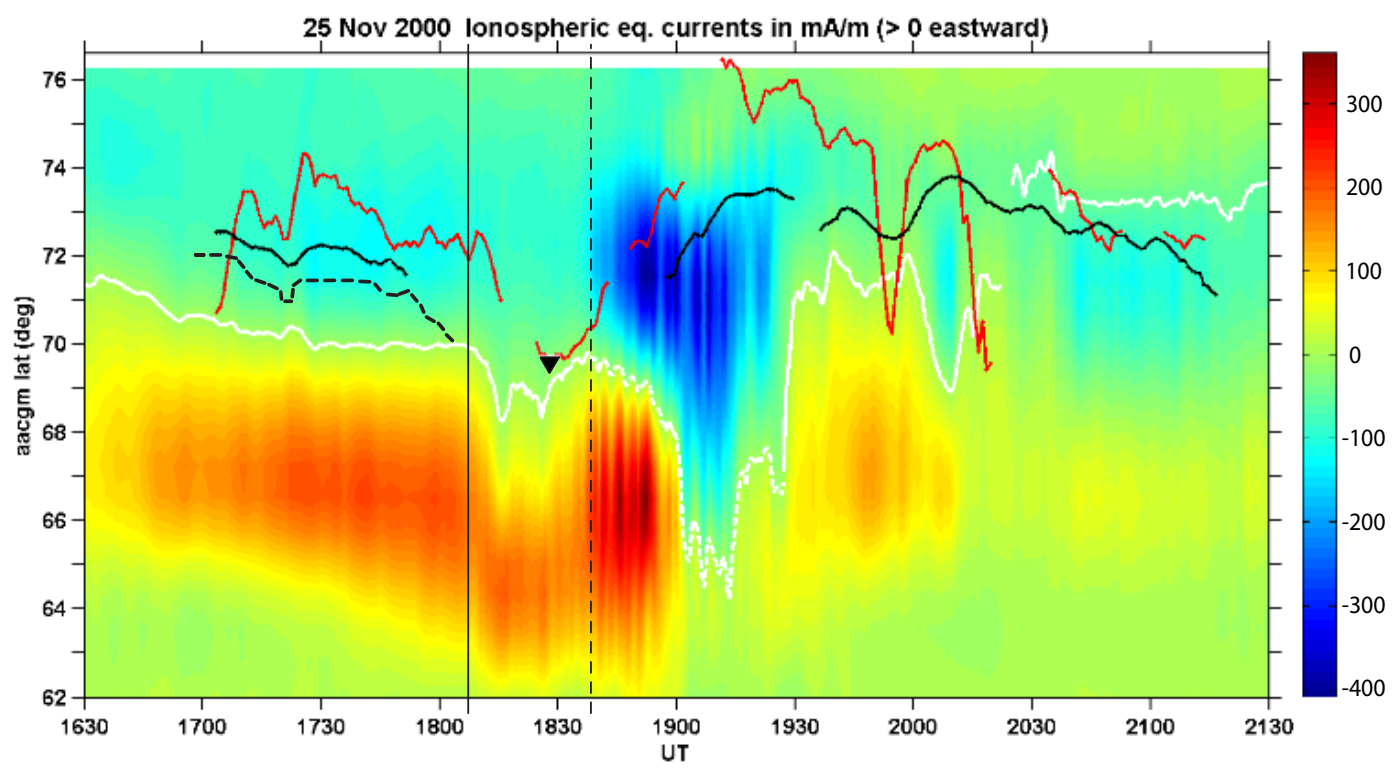

Fig. 8. Equivalent east-west currents calculated from the MIRACLE magnetometer data. Red colour indicates eastward and blue westward flowing electrojet in $\mathrm{mA} / \mathrm{m}$ (scale on the right). The white line represents the magnetic convection reversal boundary and the Harang discontinuity period is shown by a dashed line. The solid black curve is the PCB by the EISCAT VHF and the red curve is the 5-min running mean of the UVI PAE boundary. The substorm onset at 18:07 UT is marked by a vertical solid line and the expansion to the EISCAT and MIRACLE MLT at 1838 UT by a dashed line. The black triangle at 18:28 UT is the DMSP F15 particle PCB (b5e) measured in the EISCAT MLT sector.

degrees polewards at about 17:21 UT. Similar, though much weaker behaviour can be also seen in the VHF PCB.

At the substorm onset at 18:07 UT, the poleward edge of the EEJ region, followed by the UVI PAE, jumped $2^{\circ}$ cgmlat equatorwards. The VHF could not see the PCB which was located equatorward of the radar f-o-v, together with the CRB (see also Fig. 6a). After 18:25 UT the EEJ pattern started to move polewards and a few minutes later the UVI PAE followed. The DMSP F15 satellite was crossing the EISCAT MLT from south to north at 18:28 UT and the particle data of the spacecraft showed a clear poleward particle boundary (b5e) at a latitude $69.6^{\circ}$ (black triangle in Fig. 8), just equatorward of the UVI PAE boundary (DMSP data not shown). The b5e boundary represents the poleward edge of the auroral oval as determined by an abrupt drop in the electron energy flux (Newell et al., 1996a,b).

At 18:36 UT the eastward electrojet started to intensify and the MCRB stopped moving polewards. Two minutes later also the westward electrojet on the poleward side started to intensify. From the Polar UVI images it can be seen that the intensification of the electrojets was associated with the intense auroral activity intrusion from the east to the EISCAT/MIRACLE MLT sector (Fig. 7c). The UVI PAE boundary continued poleward motion together with the reappearing VHF PCB.

After 18:53 UT the WEJ expanded abruptly by several degrees to lower latitudes. This was accompanied by fading away of the most intense precipitation at the EISCAT MLT at 19:01 UT (Fig. 7e). After the Polar UVI data gap 19:0419:09 UT the UVI PAE boundary appeared at a very high latitude of about $76^{\circ}$. However, the emissions were weak and the intensity latitude profile was flat making the determination of the PAE boundary very uncertain. In addition, the wobble of the Polar satellite may have stretched the auroral forms polewards. The VHF PCB remained below $74^{\circ}$ cgmlat.

After about 19:13 UT, the eastward electrojet recovered, first at latitudes below $67^{\circ}$, in association with the weakening of the WEJ. From 19:27 UT onwards the equivalent current pattern was again dominated by the eastward electrojet, although with a lower intensity level. The westward electrojet intensified for a short period at 20:05 UT, associated with a poleward excursion of the PCB. After 20:22 UT the WEJ appeared in the post-midnight sector and the UVI PAE and the VHF PCB together followed closely the poleward edge of the westward electrojet.

\subsection{Harang discontinuity}

After 18:38 UT an intense westward electrojet formed on the poleward side of the intensifying eastward electrojet. The WEJ expanded from the east, probably rotating the whole current pattern to an earlier MLT. By 19:00 UT the WEJ region had expanded equatorward down to latitudes $65^{\circ} \mathrm{cgm}-$ lat. During this time interval, between 18:38 and 19:00 UT, 
the MIRACLE magnetometer stations showed a change from positive to negative $\mathrm{X}$, which is the original definition of the Harang discontinuity near magnetic midnight (Heppner, 1972). This MCRB is shown by a white dashed line in Fig. 8. Within the HD region, both of the electrojets had periodic, about 3-min fluctuations, whose effect can be seen in oscillatory motion of the MCRB. After 19:13 UT the MCRB moved poleward and the electrojets weakened, while the most intense auroral activity had already faded in this MLT sector. The dynamic convection pattern after 19:22 UT was associated with the recovery of the EEJ.

Amm et al. (2000) distinguished two topologically different type of HD, "rotation-type" and "expansion-type", the former being associated with the Earth's rotation and observed during quiet and moderately active geomagnetic conditions without substorm activity, and the latter during geomagnetically disturbed periods i.e. during substorms, typically appearing in an earlier MLT sector. The Harang discontinuity period in this event represents the "expansion-type" HD.

When the WEJ associated with the Harang discontinuity intruded from the east to the EISCAT MLT sector, the UVI PAE and the VHF PCB moved rapidly in the poleward direction. Still, a part of the WEJ was flowing poleward of the polar cap boundary proxies (Fig. 8). Only after about 19:10 UT almost all of the WEJ was located equatorward of these boundaries.

Figure 8 indicates that, in the Harang discontinuity region, the poleward part of the westward equivalent electrojet was flowing poleward of the UVI PAE and the VHF polar cap boundaries. Equivalent currents are the part of the real threedimensional current system that are visible to the ground. The real east-west currents are likely to deviate to some extent from the equivalent east-west currents. The MIRACLE magnetometer Y components showed positive disturbances with quasi-periodic variations of a few minutes up to $71.5^{\circ}$ cgmlat between 18:30 and 19:00 UT (data not shown). At the same time, Polar UVI images showed structured precipitation within the auroral bulge. Hence, it is plausible that structured upward field-aligned currents were flowing from this region. In addition, there is a gap in latitudinal coverage of magnetometer stations between BJN ( $71.5^{\circ}$ cgmlat) and HOR ( $74.1^{\circ}$ cgmlat), which decreases the accuracy of the 1-D upward continuation method within the region of interest. Because of these uncertainties, more investigations within the expansion type HD should be made to verify the extension of the WEJ to the polar cap.

\subsection{Reconnection electric field}

The results of the calculated ionospheric reconnection electric field are presented in the three topmost panel in Fig. 9. The topmost panel shows the plasma drift velocity along the PCB normal, positive equatorwards. The second panel shows the same velocity component for the PCB motion. The third panel presents the calculated reconnection electric field $E_{r}$.

During the substorm growth phase, before 18:07 UT, during polar cap expansion, $E_{r}$ varied between $0-10 \mathrm{mV} / \mathrm{m}$. The magnitudes are in agreement with earlies studies, e.g. de la Beaujardiere et al. (1991) found that $E_{r}$ is less than $15 \mathrm{mV} / \mathrm{m}$ when the polar cap expands and Blanchard et al. (1997) obtained values less than $10 \mathrm{mV} / \mathrm{m}$ before a substorm onset.

Because the PCB was located equatorward of the radar measurement range, the reconnection electric field could not be calculated during the substorm onset and early expansion. In the late expansion and the recovery phases $E_{r}$ varied between 15 and $40 \mathrm{mV} / \mathrm{m}$, which are of the same order of magnitude as found in earlier studies (de la Beaujardiere et al., 1991; Blanchard et al., 1997; Østgaard et al., 2005). The electric field showed also variations with periods of $\sim 7$ $27 \mathrm{~min}$. These variations are interpreted as variable reconnection occuring in the magnetotail and have been reported in earlier studies (e.g. Østgaard et al., 2005; Aikio et al., 2008).

\subsection{Reconnection electric field and auroral emissions}

In this section, the variations in the reconnection electric field are compared to the optical auroral emissions by the Polar UVI instrument.

For a comparison with the reconnection electric field, a weighted emission intensity average was calculated for UVI images corresponding to EISCAT data points (1 min resolution, bottom panel in Fig. 9). The calculation was made from a 80-min wide MLT sector including the EISCAT beams with latitude limits of $65^{\circ}$ and $80^{\circ}$ cgmlat. The emission intensities within the MLT sector were averaged in longitude by using $0.5^{\circ}$-wide latitude bins. The final result was obtained by weighting these longitudinal averages with their area and calculating the average. The 40-min wide MLT sector was enlargened to 80-min wide sector due to that also possible auroral emission intensifications occuring close to the EISCAT but not exactly at the radar beams, would be included in the calculation.

During the growth phase $E_{r}$ intensified around 17:25 UT (line a in Fig. 9). Polar UVI showed the formation of an eastwest oriented auroral arc at the poleward edge of the oval in the evening sector within the f-o-v of EISCAT (Fig. 7a). The structure was 3 MLT hours wide and lasted about $12 \mathrm{~min}$ from 17:26 UT to 17:38 UT. The brightening of the arc could be seen as an intensification of Polar UVI intensity (bottom panel of Fig. 9) The IMF $B_{z}$ had been mainly weakly southwards for several hours loading the magnetosphere (Fig. 5). This weak reconnection burst with associated localized auroral activation is a signature of release of a small amount of the energy stored into the magnetotail before the actual substorm about $40 \mathrm{~min}$ later at 18:07 UT.

No estimates of the reconnection electric field in the early expansion phase could be obtained. The rather high $E_{r}$ values in the late expansion and early recovery phase between 


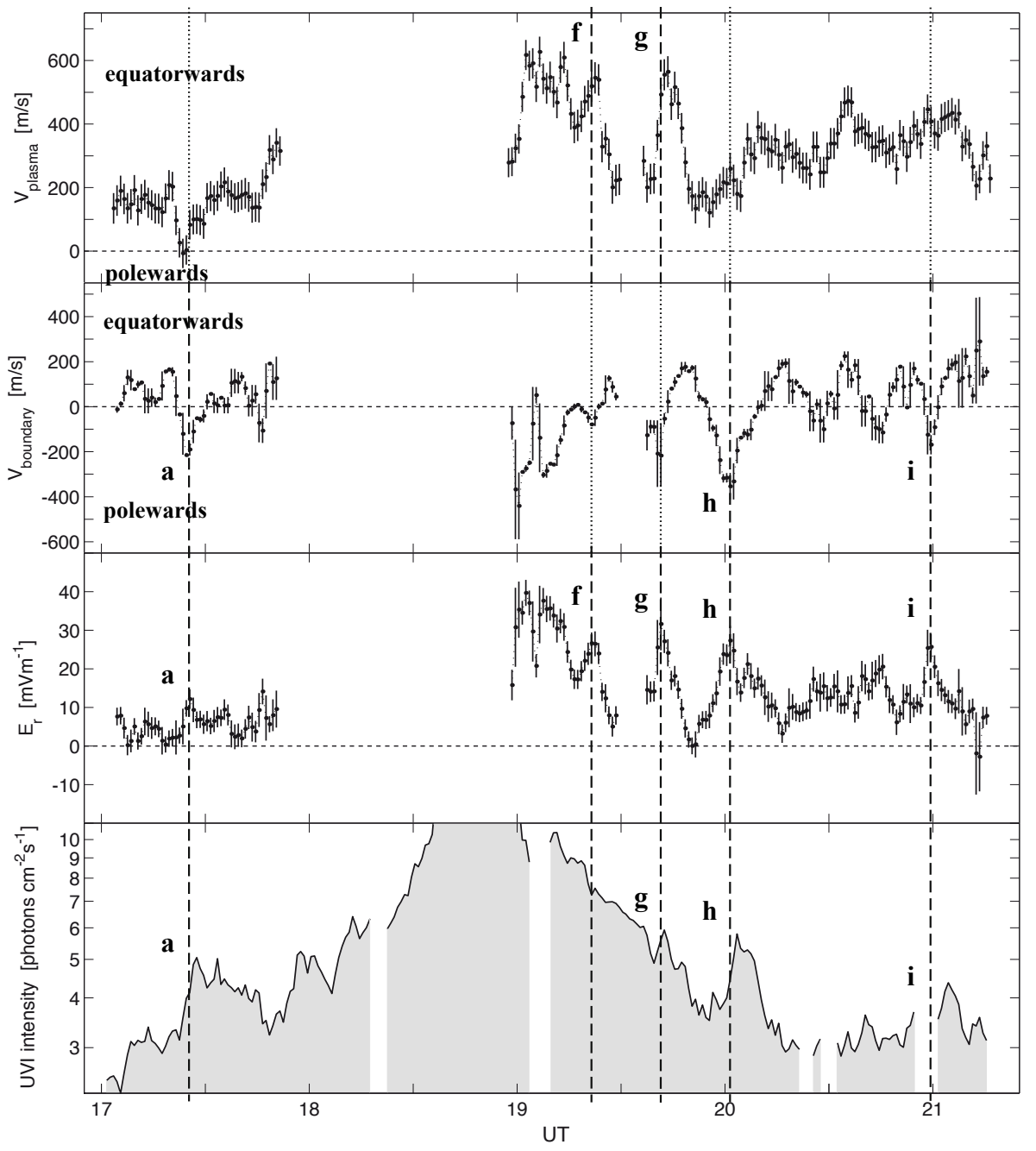

Fig. 9. Plasma drift velocity along the PCB normal, positive equatorwards (top panel). PCB velocity along the PCB normal, positive equatorwards (2nd panel). Ionospheric reconnection electric field, positive values indicate magnetic flux closure in the magnetotail (3rd panel). Vertical dotted lines show the maxima of the $E_{r}$ associated with auroral PBIs. The corresponding UVI frames in Fig. 9 are shown by a letter. Weighted average UV intensity (bottom panel).

18:58-19:17 UT were associated with rapid fading of bright aurora in the EISCAT local time sector at 19:00-19:03 UT while the most intense precipitation concentrated about an hour MLT westward of EISCAT (Fig. 7e).

The activation is obviously an auroral poleward boundary intensification (PBI) at the poleward boundary of the oval. PBIs are transient nightside geomagnetic disturbances with a localized auroral signature that appear at the poleward boundary of the auroral oval and can then extend equatorward inside the auroral oval (Lyons et al., 1999; Zesta et al., 2002). PBIs occur during all levels of geomagnetic activity (Lyons et al., 1998).

The intensification of $E_{r}$ which maximized at 19:41 UT (line g in Fig. 9) was associated with a localized poleward boundary intensification at the poleward boundary of the double oval (Elphinstone et al., 1995) in the EISCAT MLT sector (Fig. $7 \mathrm{~g}$ ). The UVI intensity curve showed a peak close to the $E_{r}$ maximum. The IMF $B_{z}$ had a southward excursion during the preceeding $15 \mathrm{~min}$ (Fig. 5). The PBI was about $1.5 \mathrm{~h}$ MLT wide and lasted roughly $8 \mathrm{~min}, 19: 41-$ 19:49 UT.

The next $E_{r}$ maximum, which was also associated with a PBI, occured at 20:01 UT (line $h$ in Fig. 9). The PBI was localized within about the same $1.5 \mathrm{~h}$-wide MLT range as the previous PBI. The PBI lasted about $9 \mathrm{~min}$, from 20:01 to 20:10 UT. Both $E_{r}$ and the averaged UVI intensity showed a very clear peak.

The last clear intensification in the reconnection electric field with a PBI occured about an hour later, at 20:59 UT (line $i$ in Fig. 9). Due to the gap in the UVI data, the duration of the 
PBI in Fig. 7i is not known, but the activation started before 21:01 UT and ended at about 21:10 UT. The width of the PBI was about $0.5 \mathrm{~h}$ MLT in the beginning, but it evolved quickly to multiple beads extending over $3 \mathrm{~h}$ MLT (Fig. 7j). During the maximum $E_{r}$, UVI had a data gap, but a maximum in the averaged intensity was observed about 5 min later.

From the second panel of Fig. 9 it can be seen that all of the enhancements in $E_{r}$ were associated with a poleward contracting polar cap boundary. The main factor in producing the calculated reconnection electric field was the poleward motion of the PCB in events $a, h$ and $i$. The enhancement in equatorward plasma flow was mainly responsible for reconnection electric field in events $\mathrm{f}$ and $\mathrm{g}$ (Fig. 9, top panel). The latter case is in accordance with de la Beaujardiere et al. (1994) who observed that the flow rate across the poleward boundary of the aurora was increased significantly during the periods of PBIs. De la Beaujardiere et al. concluded that the feature is associated with a local increase in the reconnection rate (in accordance with the Eq. 3) with qualitatively estimated peak values of the order of $25 \mathrm{mV} / \mathrm{m}$.

Besides the PBIs in the 80-min wide MLT sector centered at EISCAT that are described above, PBIs occurred also in other MLT sectors. In the growth phase, several eastwest oriented PBIs appeared, typically between 21:00 and 22:00 MLT. The brightenings were about 2 MLT wide and lasted from $3 \mathrm{~min}$ to $15 \mathrm{~min}$. In the recovery phase, a few additional PBIs could be distinguished.

\section{Summary and discussion}

We have studied some specific aspects of the reconnection process that can be related to high-latitude boundaries. The dynamics of the polar cap boundary in the evening sector during a substorm on 25 November 2000 were examined by using EISCAT incoherent scatter radar measurements. As a measure of the nightside reconnection rate, the local ionospheric reconnection electric field was estimated by the method introduced by Vasyliunas (1984), where the electric field is calculated by using plasma flow across the PCB. The plasma drift velocity was calculated from the dual-beam measurements of the EISCAT VHF radar, and the PCB was determined using EISCAT measurements on both the mainland and Svalbard by using the method by Aikio et al. (2006).

The VHF PCB was compared with the poleward auroral emission boundary extracted from global optical images of the Polar UV Imager. On the average, the PAE boundary was located $0.7^{\circ}$ poleward of the EISCAT PCB in this event, though large scatter occured in individual points. The most probable cause for the difference in the UVI PAE and the VHF PCB locations is the wobble of the Polar satellite, which causes smearing of UVI images along the wobble direction. In this case, the wobbling was unfortunately in the direction in which the PAE boundary was determined ( 10:00-22:00 MLT). During one DMSP overflight, a close co-location of the b5e boundary (poleward edge of the oval) and the PAE boundary was found (the PCB was at too low a latitude at that moment for the EISCAT VHF to see it).

The calculation of the 2-D plasma velocity vectors allowed the determination of the convection reversal boundary from the EISCAT data. A striking feature was the similar temporal evolution of the PCB (from $T_{e}$ data) and the CRB (from plasma velocity data), lending credence for the method of PCB determination. The CRB was observed to follow the motion of the PCB and to be located $0.5-1^{\circ}$ cgmlat equatorward of the PCB. The offset is consistent with the results by Sotirelis et al. (2005), who compared SuperDARN HF radar boundaries with DMSP particle boundaries. Sotirelis et al. found an equatorward offset of the CRB relative to the PCB that varies according to the local time from zero near noon to $\sim 1^{\circ}$ near dawn and dusk and is largest near midnight. In the early morning sector, offset as large as $3-4^{\circ}$ has been observed (Amm et al., 2003). The PCB-CRB offset is interpreted to result from a small viscous-like interaction between the magnetosheath and the low-latitude boundary layer, resulting in antisunward flow on closed field lines next to the polar cap boundary (Sotirelis et al., 2005, and references therein).

The VHF PCB, the CRB, and the UVI PAE boundary were studied in a framework of the 1-D ionospheric equivalent east-west electrojets calculated from the MIRACLE magnetometer measurements by using the upward continuation method by Vanhamäki et al. (2003). During the substorm growth phase, all the boundaries showed a similar drift motion equatorwards on the poleward side of the eastward electrojet region. The UVI PAE boundary was generally located poleward of the VHF PCB with varying distances.

The onset of the substorm expansion occured about $2 \mathrm{~h}$ MLT east of the observed local time sector and was associated with a sudden equatorward leap of $2^{\circ}$ of the EEJ region. After $31 \mathrm{~min}$ a dynamical electrojet pattern was observed to expand to the EISCAT MLT in association with intense auroral activity. The current pattern was formed by intense westward electrojet on the poleward side of the eastward electrojet and was in the f-o-v of EISCAT and MIRACLE for about $50 \mathrm{~min}$. We interpret the current system to represent a dynamical "expansion-type" Harang discontinuity, after classification by Amm et al. (2000). Within the Harang discontinuity region, the UVI PAE and the VHF PCB boundaries moved rapidly poleward within the WEJ. A part of the calculated equivalent westward electrojet was flowing poleward of the boundaries.

Later in the recovery phase, the boundaries generally moved equatorwards. After shifting to the post-midnight sector, the VHF PCB and the UVI PAE followed together the poleward edge of the WEJ. The separation of the CRB and the MCRB in the growth and the recovery phases is consistent with earlier evening sector studies where the MCRB was found to be typically located $1-2^{\circ}$ cgmlat equatorward of the CRB (Fontaine and Peymirat, 1996; Amm, 1998). In 
the post-midnight sector the MCRB was found to be located $1-2^{\circ}$ poleward of the $\mathrm{CRB}$, which is close to the values of $0.5-1^{\circ}$ observed earlier by Amm et al. (2003). It is suggested that the shift is due to the field-aligned currents flowing in the vicinity of the HD (Amm, 1998; Amm et al., 2003).

The calculated local ionospheric reconnection electric field was found to vary between 0 and $10 \mathrm{mV} / \mathrm{m}$ during the substorm growth phase. During the late expansion and recovery phases, values up to $40 \mathrm{mV} / \mathrm{m}$ were observed. The values are in agreement with earlier studies (de la Beaujardiere et al., 1991; Blanchard et al., 1997; Østgaard et al., 2005). During the latter period, the electric field showed also variations with periods of $\sim 7-27 \mathrm{~min}$. Similar periods have been reported in previous studies and interpreted as variable reconnection occuring in the magnetotail (e.g. Østgaard et al., 2005; Aikio et al., 2008).

Comparison of the reconnection electric field with the Polar UVI data showed a clear correlation between intensifications of $E_{r}$ and auroral poleward boundary intensifications (PBIs). The PBIs appeared within one minute of the ionospheric reconnection electric field maxima and lasted 5-12 min. The PBI-associated $E_{r}$ maxima values were $12 \mathrm{mV} / \mathrm{m}$ in the growth phase and $27 \mathrm{mV} / \mathrm{m}, 32 \mathrm{mV} / \mathrm{m}$, $27 \mathrm{mV} / \mathrm{m}$ and $26 \mathrm{mV} / \mathrm{m}$ in the recovery phase. The widths of the PBIs were $3 \mathrm{~h}$ MLT in the growth phase and $1.5 \mathrm{~h}$ MLT in the recovery phase. For the last PBI in the late recovery/quiet phase the width was initially $0.5 \mathrm{~h}$ MLT but then the PBI evolved into beads covering about $3 \mathrm{~h}$ MLT.

In all the five cases, the PCB contracted poleward, but in two cases during the substorm recovery phase, enhanced plasma flow velocity equatorward, across the PCB, was the main factor in producing the enhanced reconnection electric field. An enhanced southward plasma velocity in association with arc intensifications at the poleward auroral boundary have been observed also by de la Beaujardiere et al. (1994).

It has been suggested that when the UVI intensity is high, there is a high ionospheric conductivity and significant frictional coupling between the ionospheric plasma and the neutral atmosphere. Then plasma flows are retarded and it is the PCB that moves. When the conductivity is low, ionospheric flows are excited rather than motions of the PCB (Boudouridis et al., 2008). In this study, the PCB motions were generally associated with bright emissions at the boundary and thus with high conductivities. However, the largest plasma flow in event $g$ was also associated with rather intense emissions, in contradiction with Boudouridis et al. (2008). The other plasma flow event $f$ was indeed associated with less intense emissions at the boundary. To make clear conclusions, more events should be studied.

PBIs are generally considered as ionospheric signatures of longitudinally narrow earthward plasma sheet flow bursts, bursty bulk flows (BBFs) (Lyons et al., 2002, and references therein). For the source of PBIs and BBFs, two processes have been suggested: localized distant $\mathrm{X}$ line reconnection bursts (Sergeev et al., 2000) and global ULF pulsa- tion modes of the magnetosphere (Lyons et al., 2002). Zesta et al. (2002) found the PBIs are either equatorward extending (N-S or E-W structures) or non-equatorward extending. They suggested that the equatorward extending north-south PBIs would be associated with longitudinally narrow BBFs whereas the wider east-west oriented structures could be associated with the global ULF modes. The non-equatorward extending PBI structures would be associated with a shear instability at the separatrix boundary. However, recently Zesta et al. (2006) deduced that every equatorward extending PBI structure they studied, including both north-south and eastwest structures, was associated with a fast flow channel in the tail within the same local time sector.

Aikio et al. (2008) found periodic poleward expansions of the PCB which were associated with intensifications of the WEJ in the vicinity of the PCB in a recovery phase of a substorm. Since no signatures of global ULF waves were found, they suggested that enhanced reconnection bursts took place in the tail. In this study, at least one clear localized WEJ enhancement with a simultaneous poleward expanding PCB was observed after 20:00 UT, and by utilizing the dualbeam VHF measurements we were able to show that it indeed was associated with an enhanced reconnection electric field (line h in Fig. 9).

The spatial resolution of the Polar UV Imager was not high enough in this case to tell whether or not the PBIs were narrow auroral structures that propagated equatorward. However, they all, including the last one with multiple beads, were associated with enhanced reconnection, which suggests that the PBIs were a consequence of temporarily enhanced longitudinally localized magnetic flux closure in the magnetotail.

Acknowledgements. The authors are grateful to Ritva Kuula for help in the EISCAT data analysis. The EISCAT is an international association supported by research organisations in China (CRIRP), Finland (SA), France (CNRS, till end 2006), Germany (DFG), Japan (NIPR and STEL), Norway (NFR), Sweden (VR), and the United Kingdom (STFC). The authors thank George Parks and Matt Fillingim for the Polar UVI data, and N. Ness, CDAWEB and SPDF/OMNIWeb for the ACE data and the SPDF/Modelweb for IGRF/DGRF-model parameters. The MIRACLE network is operated as an international collaboration under the leadership of the Finnish Meteorological Institute. The DMSP particle detectors were designed by Dave Hardy of AFRL, and data obtained from JHU/APL. We thank D. Hardy, F. Rich, and P. Newell for its use. The Sub-Auroral Magnetometer Network data (SAMNET) is operated by the Department of Communications Systems at Lancaster University (UK) and is funded by the Science and Technology Facilities Council (STFC). The work by AK has been supported by the Academy of Finland (project 115920).

Topical Editor I. A. Daglis thanks L. Lyons and another anonymous referee for their help in evaluating this paper. 


\section{References}

Aikio, A. T., Pitkänen, T., Kozlovsky, A., and Amm, O.: Method to locate the polar cap boundary in the nightside ionosphere and application to a substorm event, Ann. Geophys., 24, 1905-1917, 2006, http://www.ann-geophys.net/24/1905/2006/.

Aikio, A. T., Pitkänen, T., Fontaine, D., Dandouras, I., Amm, O., Kozlovsky, A., Vaivdas, A., and Fazakerley, A.: EISCAT and Cluster observations in the vicinity of the dynamical polar cap boundary, Ann. Geophys., 26, 87-105, 2008, http://www.ann-geophys.net/26/87/2008/.

Amm, O.: Method of characteristics in spherical geometry applied to a Harang-discontinuity situation, Ann. Geophys., 16, 413424, 1998, http://www.ann-geophys.net/16/413/1998/.

Amm, O., Janhunen, P., Opgenoorth, H. J., Pulkkinen, T. I., and Viljanen, A.: Ionospheric shear flow situations observed by the MIRACLE network, and the concept of Harang Discontinuity, AGU monograph on magnetospheric current systems, Geophysical Monograph, 118, 227-236, 2000.

Amm, O., Aikio, A., Bosqued, J.-M., Dunlop, M., Fazakerley, A., Janhunen, P., Kauristie, K., Lester, M., Sillanpää, I., Taylor, M. G. G. T., Vontrat-Reberac, A., Mursula, K., and André, M.: Mesoscale structure of a morning sector ionospheric shear flow region determined by conjugate Cluster II and MIRACLE ground-based observations, Ann. Geophys., 21, 1737-1751, 2003, http://www.ann-geophys.net/21/1737/2003/.

Baker, J. B., Clauer, C. R., Ridley, A. J., Papitashvili, V. O., Brittnacher, M. J., and Newell, P. T.: The nightside poleward boundary of the auroral oval as seen by DMSP and the ultraviolet imager, J. Geophys. Res., 105, 21267-21280, 2000.

Baker, K. and Wing, S.: A new magnetic coordinate system for conjugate studies at high latitudes, J. Geophys. Res., 94 , 91399143, 1989.

de la Beaujardiere, O., Lyons, L.R., and Friis-Christensen, E.: Sondrestrom radar measurements of the reconnection electric field, J. Geophys. Res., 96, 13907-13912, 1991.

de la Beaujardiere, O., Lyons, L.R., Ruohoniemi, J. M., FriisChristensen, E., Danielsen, C., Rich, F. J., and Newell, P. T.: Quiet-time intensifications along the poleward auroral boundary near midnight, J. Geophys. Res., 99, 287-298, 1994.

Blanchard, G. T., Lyons, L. R., de la Beaujardiere, O., Doe, R. A., and Mendillo, M.: Measurement of the magnetotail reconnection rate, J. Geophys. Res., 101, 15265-15276, 1996.

Blanchard, G. T., Lyons, L. R., and de la Beaujardiere, O.: Magnetotail reconnection rate during magnetospheric substorms, J. Geophys. Res., 102, 24303-24312, 1997.

Boudouridis, A., Lyons, L. R., Zesta, E., Ruohoniemi, J. M., and Lummerzheim, D.: Nightside flow enhancement associated with solar wind dynamic pressure driven reconnection, J. Geophys. Res., 113, A12211, doi:10.1029/2008JA013489, 2008.

Cowley, S. W. H: Magnetosphere-ionosphere interactions: a tutorial review, AGU monograph on magnetospheric current systems, Geophysical Monograph, 118, 91-106, 2000.

Cowley, S. W. H. and Lockwood, M.: Excitation and decay of solar wind-driven flows in the magnetosphere-ionosphere system, Ann. Geophys., 10, 103-115, 1992.

Dungey, J. W.: Interplanetary field and the auroral zones, Phys. Res. Lett., 6, 47-48, 1961.

Elphinstone, R. D., Hearn, D. J., Cogger, L. L., et al.: The double oval auroral distribution, 2., The most poleward arc system and the dynamics of the magnetotail, J. Geophys. Res., 100, 1209312102, 1995.

Fontaine, D. and Peymirat, C.: Large-scale distributions of ionospheric horizontal and field-aligned currents inferred from EISCAT, Ann. Geophys., 14, 1284-1296, 1996,

http://www.ann-geophys.net/14/1284/1996/.

Heppner, J. P.: The Harang discontinuity in auroral belt ionospheric currents, Geophys. Norv., 29, 105-120, 1972.

Hubert, B., Milan, S. E., Grocott, A., Blockx, C., Cowley, S. W. H., and Gérard, J.-C.: Dayside and nightside reconnection rates inferred from IMAGE FUV and Super Dual Auroral Radar Network, J. Geophys. Res., 111, A03217, doi:10.1029/2005JA011140, 2006.

Kauristie, K., Weygand, J., Pulkkinen, T.I., Murphree, J. S., and Newell, P. T.: Size of the auroral oval: UV ovals and precipitation boundaries compared, J. Geophys. Res., 104, 2321-2331, 1999.

Koskinen, H. E. J. and Pulkkinen, T. I.: Midnight velocity shear zone and the concept of Harang discontinuity, J. Geophys. Res., 100, 9539-9547, 1995.

Liou, K., Meng, C.-I, Newell, P. T., Takahashi, K., Ohtani, S.-I., Lui, A. T. Y., Brittnacher, M., and Parks, G.: Evaluation of lowlatitude Pi2 pulsations as indicators of substorm onset using Polar ultraviolet imagery, J. Geophys. Res., 105, 2495-2505, 2000.

Lyons, L. R., Blanchard, G. T., Samson, J. C., Ruohoniemi, J. M., Greenwald, R. A., Reeves, G. D., and Scudder, J. D.: Near Earth plasma sheet penetration and geomagnetic disturbances, AGU monograph on new perspectives on the Earth's magnetotail, Geophysical Monograph, 105, 241-257, 1998.

Lyons, L. R., Nagai, T., Blanchard, G. T., Samson, J. C., Yamamoto, T., Mukai, T., Nishida, A., and Kokubun, S.: Association between Geotail plasma flows and auroral poleward boundary intensifications observed by CANOPUS photometers, J. Geophys. Res., 104, 4485-4500, 1999.

Lyons, L. R., Zesta, E., Xu, Y., Sanchez, E. R., Samson, J. C., Reeves, G. D., Ruohoniemi, J. M., and Sigwarth, J. B.: Auroral poleward boundary intensifications and tail bursty flows: A manifestation of a large-scale ULF oscillation, J. Geophys. Res., 107, 1352, doi:10.1029/2001JA000242, 2002.

Milan, S. E., Lester, M., Cowley, S. W. H., Oksavik, K., Brittnacher, M., Greenwald, R. A., Sofko, G., and Villain, J.-P.: Variations in the polar cap area during two substorm cycles, Ann. Geophys., 21, 1121-1140, 2003, http://www.ann-geophys.net/21/1121/2003/.

Milan, S. E.: Dayside and nightside contributions to the cross polar cap potential: placing an upper limit on a viscous-like interaction, Ann. Geophys., 22, 3771-3777, 2004, http://www.ann-geophys.net/22/3771/2004/.

Newell, P. T., Feldstein, Y. I., Galperin, Y. I., and Meng, C.-I.: Morphology of nightside precipitation, J. Geophys. Res., 101, 10737-10748, 1996a.

Newell, P. T., Feldstein, Y. I., Galperin, Y. I., and Meng, C.-I.: Correction to "Morphology of nightside precipitation" by Patrick T. Newell, Yasha I. Feldstein, Yuri I. Galperin,and Ching-I. Meng, J. Geophys. Res., 101, 17419-17421, 1996b.

Østgaard, N., Moen, J., Mende, S. B., Frey, H. U., Immel, T. J., Gallop, P., Oksavik, K., and Fujimoto, M.: Estimates of magnetotail reconnection rate based on IMAGE FUV and EISCAT measurements, Ann. Geophys., 23, 123-134, 2005, http://www.ann-geophys.net/23/123/2005/. 
Parks, G., Brittnacher, M., Chen, L. J., Elsen, R., McCarthy, M., Germany, G., and Spann, J.: Does the UVI on Polar detect cosmic snowballs, Geophys. Res. Lett., 24, 3109-3112, 1997.

Senior, C., Delcourt, D., Cerisier, J.-C., Hanuise, C., Villain, J.P., Greenwald, R. G., Newell, P. T., and Rich, F. J.: Correlated observations of the boundary between polar cap and nightside auroral zone by HF radars and the DMSP satellite, Geophys. Res. Lett., 21, 221-224, 1994.

Sergeev, V. A.: Multiple-spacecraft observation of a narrow transient plasma jet in the Earths plasma sheet, Geophys. Res. Lett., 27, 851-854, 2000.

Siscoe, G. L. and Huang T. S.: Polar cap inflation and deflation, J. Geophys. Res., 90, 543-547, 1985.

Sotirelis, T., Ruohoniemi, J. M., Barnes, R. J., Newell, P. T., Greenwald, R. A., Skura, J. P., and Meng, C.-I.: Comparison of SuperDARN radar boundaries with DMSP particle precipitation boundaries, J. Geophys. Res., 110, A06302, doi:10.1029/2004JA010732, 2005.

Tanaka, T.: Configuration of the magnetosphere-ionosphere convection system under northward IMF conditions with nonzero IMF $B_{y}$, J. Geophys. Res., 104, 14683-14690, 1999.

Torr, M., Torr, D. G., Zukic, M., Johnson, R. B., Ajello, J., Banks, P., Clark, K., Cole, K., Keffer, C., Parks, G., Tsurutani, B., and Spann, J.: A far ultraviolet imager for the International SolarTerrestrial Physics Mission, Space Sci. Rev., 71, 329-383, 1995.
Vanhamäki, H., Amm, O., and Viljanen, A.: 1-dimensional upward continuation of the ground magnetic field disturbance using spherical elementary current systems, Earth Planets Space, 55, 613-625, 2003.

Vasyliunas, V. M.: Steady state aspects of magnetic field line merging, AGU monograph on magnetic reconnection in space and laboratory plasmas, Geophysical Monograph, 30, 25-31, 1984.

Weimer, D. R. and King, J. H.: Improved calculations of interplanetary magnetic field phase front angles and propagation time delays, J. Geophys. Res., 113, A01105, doi:10.1029/2007JA012452., 2008a.

Weimer, D. R. and King, J. H.: Correction to "Improved calculations of interplanetary magnetic field phase front angles and propagation time delays", J. Geophys. Res., 113, A07106, doi:10.1029/2008JA013075., 2008b.

Zesta, E., Donovan, E., Lyons, L., Enno, G., Murphree, J. S., and Cogger, L.: Two-dimensional structure of auroral poleward boundary intensifications, J. Geophys. Res., 107, 1350-1369, doi:10.1029/2001JA000260, 2002.

Zesta, E., Lyons, L., Wang, C.-P., Donovan, E. Frey, H., and Nagai, T.: Auroral poleward boundary intensifications (PBIs): Their two-dimensional structure and associated dynamics in the plasma sheet, J. Geophys. Res., 111, A05201, doi:10.1029/2004JA010640., 2006. 